\title{
El concepto de realidad en los Discursos de Maquiavelo
}

\section{Introducción.}

La tarea de determinar cuál es el concepto de realidad que Maquiavelo utiliza entraña ciertas dificultades, dado que Maquiavelo no pretende en absoluto una metafísica, por lo que sus afinnaciones sobre la realidad han de ser leídas entre líneas, como presupuestos de sus afirmaciones de carácter sociopolítico. Baste para ilustrar esta dificultad dos interpretaciones profundamente divergentes de su idea de realidad:

a) Modelo clósico del ciclo natural Para Augustin Renaudet a los escritos de Maquiavelo subyace la idea de un devenir cíclico de lo real, de un etemo retomo: el mundo humano estaría sometido a una rígidas leyes que no harían sino repetirse sin fin. A diferencia de Leonardo da Vinci, que confía en el progreso de las sociedades humanas, Maquiavelo sería el exponente de una concepción fatalista de la historia. Sin duda este fatalismo deja algún resquicio para la libertad humana, pues el hombre, en el medida que conoce la historia pasada puede acceder a la leyes del mundo sociopolítico, y así saber prevenir y aprovechar las oportunidades que la fortuna nos brinda ${ }^{1}$. De ser esto así, habría que decir que en el campo filosófico, por mucho que Maquiavelo haya de ser considerado el fundador de una nuova scienza, la ciencia política, de hecho su pensamiento filosófico sería más bien clásico. Maquiavelo seguiría pensando, como el mismo Aristóteles, las realidades sociales en términos de naturaleza. Evidentemente, el secretario florentino se habría liberado de toda la metafísica hilemorfista, inmediatamente perceptible incluso en los escritos políticos del Estagirita, pero continuaría como éste inscribiendo el mundo social e histórico en el continuo proceso de nacimiento, desarrollo, degeneración y muerte que rige el mundo biológico. La novedad estaría entonces en que este universo natural ya no es contemplado en términos de acto y potencia, sino en términos mucho más positivos, atomistas y, en definitiva, técnicos. Frente a un mundo de esencias aparecería aquí un mundo regido por el aparente azar de los choques entre individuos dotados de fuerzas e intereses contrapuestos que, para la mirada atenta del científico, acabaría desvelando tendencias estrictamente 
necesarias y legales ${ }^{2}$. El conocimiento de esta mecánica social serviría entonces para desarrollar una verdadera técnica política dentro de los estrictos márgenes impuestos por la fatalidad o, como Maquiavelo dice, por la fortuna.

b) Teoría de la historia. Una interpretación muy distinta es la de Ana Martínez Arancón ${ }^{3}$. Para ella Maquiavelo comienza, sin duda, considerando las realidades históricas y sociales como fenómenos naturales. Pero esto no es más que, por así decirlo, un momento negativo: sería el modo como Maquiavelo se distancia de las explicaciones religiosas y morales de lo social, para concentrarse en su puro valor político. Pero es este valor político, y no el mecánico o el físico el que verdaderamente le interesa ${ }^{4}$. En realidad, la política estaría para Maquiavelo muy lejos de los meros determinismos propios de un ciclo natural. El estado no sería un hecho natural, como en los clásicos, sino un producto de la acción humana, un artificios. Por esto, "Maquiavelo no cree que este ciclo sea inmutable o que constituya una especie de destino circular e insoslayable. Precisamente la historia, al proporcionamos conocimiento, nos da la posibilidad de romper el círculo. El conocimiento es poder"'. Frente a la explicación clásica de la realidad en términos de pura naturaleza aparecería aquí una visión estrictamente histórica que, en la medida en que se separa radicalmente de toda interpretación teológica del mundo, anuncia una visión del mundo social propia de la modemidad ilustrada.

Ahora bien, esta lectura de Maquiavelo contiene algunos puntos oscuros. En primer lugar, no parece del todo atinado sostener que la consideración de las realidades sociopolíticas como realidades naturales sea un mero recurso metodológico para eliminar de las mismas toda dimensión religiosa o moral. Semejante estrategia tendría sentido en un contexto donde se presupone el carácter no natural de los fenómenos éticos, como es característico de la modemidad después de la crítica de Hume a la así llamada "falacia naturalista". Pero en el contexto de Maquiavelo y en todo el pensamiento clásico no hay una disociación entre naturaleza y moral. Aristóteles elabora toda su ética y su política (que para él no es otra cosa que la parte culminante de la ética) en esta perspectiva: el comportamiento humano y la vida social obedecen para él a unas leyes de carácter natural las poseen en cuanto tales un valor ético. En la perspectiva cristiana, la naturaleza en cuanto creación es también un ámbito donde se puede legítimamente leer la voluntad divina con sus implicaciones morales. Por esto habría que decir que a Maquiavelo no le bastaba en absoluto con tratar las sociedades humanas como realidades naturales para borrar de un plumazo su carácter ético o religioso.

$Y$ es que, en segundo lugar, lo que hace Maquiavelo no es apelar a la naturaleza para librarse de la moral, sino entender la naturaleza misma en términos no morales. Para Aristóteles, como en general para todo el pensamiento helénico, la realidad tiene en sí misma un carácter de bien. En su virtud, la bondad moral y política no consiste en otra cosa que en la realización de todas las potencialidades que un determinado ente lleva inscritas en su misma naturaleza. La bondad es 
perfección, es hermosura o realización de una forma. Al contrario de Platón, que entiende estas formas como separadas, en Aristóteles las fonnas entran en la constitución misma del ente. Una realidad será tanto más buena cuanto más actualice su propia esencia natural. Esto puede aplicarse también a la pólis: el régimen ideal no es para Aristóteles otro que el que satisfaga la esencia misma de la ciudadestado, y por eso a su investigación sobre el mejor de los regímenes políticos es precedida (al menos en la disposición tradicional del texto) por la determinación de cuáles son los rasgos esenciales de la ciudad-estado. Si la "república" es para Aristóteles el mejor de los regímenes posibles, lo es por ser la mejor realización de esa esencia formal. Otros criterios, como la estabilidad, son para Aristóteles axiomas derivados de este postulado metafísico fundamental. ¿Tiene entonces razón Renaudet? Para ponderar esto lo mejor será acudir al texto del mismo Maquiavelo.

\section{Nuevo método.}

El secretario florentino comienza sus Discursos advirtiendo que se ha decidido entrar por un camino que no ha recorrido aún nadie, para acto seguido remitirse a la antigüedad clásica como modelo que las repúblicas modemas han de seguir? Ciertamente, Maquiavelo sabe que no toda apelación al pasado es siempre objetiva, dada la tendencia humana a idealizar los tiempos pretéritos, pero en el caso de la Roma clásica no le cabe la menor duda de que ésta ha sido efectivamente muy superior en su organización política al presente y que, por tanto, es legítimo tomarla como paradigma ${ }^{8}$. Ahora bien, es evidente que la novedad del planteamiento de Maquiavelo no está en la referencia a la antigüedad clásica, lo cual era común a todo el renacimiento, sino más bien en el carácter mismo de esa referencia: se trata de llevar a cabo un estudio positivo de las realidades políticas del pasado. Maquiavelo se referirá a la historia clásica de Roma, utilizando principalmente a Tito Livio, para desde ahí obtener algún postulado o hipótesis general que después tratará de ver corroborado en el presente, especialmente en la práctica política de Florencia que Maquiavelo conoce de modo privilegiado.

La consideración empírica de las realidades políticas es, como tantas veces se ha dicho, la gran innovación metodológica de Maquiavelo. Sin embargo, este carácter positivo de sus estudios, si bien justificaría echar mano de los datos conocidos del pasado, no es todavía suficiente justificación de la continua apelación de los Discursos al pasado. Para entender esto es menester comenzar por señalar que este nuevo método, fundamentalmente empírico e inductivo, tiene que contar con la continuidad del universo que describe. No se trata simplemente de la imposibilidad de pasar de constataciones particulares a leyes universales, pues el método de Maquiavelo tiene también un momento constructivo de elaboración de hipótesis generales que luego se habrán de validar en la experiencia. Lo que sucede es que la construcción de leyes universales, aun manteniendo su carácter hipotético y aproximativo, presupone una continuidad entre el ámbito de donde se toman los datos positivos y el ámbito donde estas hipótesis se corroboran, es decir, una 
continuidad entre la historia romana clásica y la historia de Florencia. Esta continuidad es el presupuesto general sobre el que se pueden construir todas las demás hipótesis. Pero mientras las demás hipótesis tiene un origen inmediato en los datos históricos pasados o presentes, este presupuesto general es trans-empírico y supone recurrir a algún tipo de filosofía de la historia.

\section{La rueda de la fortuna.}

Por esto se entiende que Maquiavelo, después de habemos anunciado que él va a comenzar un camino nuevo, pase acto seguido a hablamos, en primer lugar, de los orígenes de la ciudad y, en segundo lugar, de la sucesión de los distintos regímenes políticos, tal como podemos encontrar también en filósofos como Platón o Aristóteles ${ }^{9}$. Pero ahora, a diferencia de los filósofos clásicos, interesados en determinar cuál es la esencia formal de la ciudad, Maquiavelo sólo se preocupa de mostrar que existe una lógica interna en la sucesión de los distintos regímenes políticos que permite establecer una continuidad entre el pasado y el presente. Esta continuidad no consiste en desarrollo lineal, como después pensará la filosofía ilustrada de la historia, sino en un movimiento circular en el que se repiten indefinidamente las mismas formas políticas ${ }^{10}$. El mismo Maquiavelo admite que "raras veces retoman las mismas formas políticas" ", pero atribuye esto a su limitada vida: "si no sucediera esto, un país podría dar vueltas por tiempo indefinido en la rueda de las formas de gobiemo"'12. Esta rueda en la que cada república, de no extinguirse, giraría etemamente, no es otra cosa que lo que Maquiavelo denominará fortuna ${ }^{13}$.

El supuesto de la existencia de tal rueda de las formas de gobiemo, para no ser gratuito, se apoya en un presupuesto aún más general: los hombres son siempre iguales; "nacen, viven y mueren siempre de la misma manera"14. Mientras que Aristóteles buscaba la lógica intema de lo político en la esencia de un organismo llamado pólis, en sí mismo superior a sus partes, Maquiavelo se remite en última instancia a la naturaleza humana individual, de la que, por lo demás, tiene un concepto más bien pesimista: el legislador ha pensar siempre que los hombres son todos malos ${ }^{15}$, por más que esa maldad y los conflictos que genera sean, bien manejados, un factor de logros políticos positivos incluso para los partidos enfren$\operatorname{tados}^{16}$. Por ello, aunque Maquiavelo se sirve de analogías biológicas aplicadas a la república en su conjunto ${ }^{17}$, ésta no pasa para él de ser una creación humana ${ }^{18}, y$ su interés recae principalmente sobre el sujeto de las acciones políticas, que él concibe individualmente. Por eso los ciclos vitales de las repúblicas ${ }^{19}$ no descansan sobre éstas mismas, sino sobre la naturaleza de los hombres que la componen, a cuya lógica y motivaciones hay que atender: lo general es para Maquiavelo mera generalización de lo particular ${ }^{20}$.

Ahora se puede entender la continua apelación de Maquiavelo al pasado como paradigma del presente. No se trata, en realidad, de una simple exaltación del legislador original ${ }^{21}$, como pretende Renaudet ${ }^{22}$, sino de una tesis necesaria para el desarnollo de su método positivo. Ciertamente, Maquiavelo se mueve en el ámbito 
del culto renacentista a la antigüedad clásica, y comparte con su tiempo la idealización de los orígenes de las ciudades y de las religiones ${ }^{23}$. Pero el motivo último de su recurso al pasado no es ni el mito ni la búsqueda de datos positivos que permitirán forjar un futuro distinto, como diría Ana Martínez Alarcón, sino más bien el presupuesto filosófico de una naturaleza humana siempre igual a sí misma y subyacente a los avatares históricos. En tal hipótesis sería incluso pensable que determinados momentos de tal historia cíclica puedan ser entendidos como expresiones más puras de esa naturaleza. La comupción sería entonces una degeneración no debida a la simple necesidad natural (las ciudades no son organismos biológicos), sino desorganización de aquello que de suyo la naturaleza humana individualmente considerada puede dar de $\operatorname{sî}^{24}$. Esta naturaleza humana sería en definitiva la base última sobre la que giraría la rueda de la fortuna.

\section{Libertad y fortuna.}

Si éstos son sus presupuestos filosóficos, podría pensarse entonces que Maquiavelo no hace más que restaurar un determinismo universal de corte naturalista, cuyos paralelos más cercanos podrían hallarse en las filosofías del helenismo. Sin embargo, como es sabido, Maquiavelo apela continuamente a la libertad individual y a la capacidad del político para cambiar el curso de los acontecimientos. Es más, sus escritos tienen, sin duda, una intencionalidad política y pretenden justamente influir sobre la práctica de sus destinatarios. Maquiavelo no pretende hacer teoría social, sino desarrollar un tratado de técnica política, y esto no se puede hacer sin contar con algún tipo de libertad de los sujetos de la misma.

Ciertamente, cuando Maquiavelo habla de "libertad" no se refiere generalmente a esta capacidad del sujeto para intervenir en el curso de los acontecimientos, sino a la "libertad romana"2s, esto es, a la institucionalización de formas civiles de gobiemo que doten de seguridad y confianza a los ciudadanos y de eficacia a la república ${ }^{26}$. Pero sin duda Maquiavelo cuenta también con la capacidad del individuo para alterar el hilo de la historia. Lo que sucede es que le circunscribe un margen muy concreto. Dada la sucesión inexorable de las formas de gobierno en la que giran todas las repúblicas es posible, sin salirse de esta estricta legalidad, construir una república que combine distintas formas de gobierno (en concreto, la monarquía, la aristocracia y la democracia) y que, por ello, en lugar de rodar de forma pura en forma pura, se mantenga por un tiempo largo (o incluso indefinido) en esa forma mixta: es el caso de Licurgo o de Roma hasta César ${ }^{27}$. A los hombres no les estaría dado alterar la ley rígida de sucesión de las formas de gobierno, sino más bien el lograr una síntesis tal de todas ellas que pudiera prolongar la vida y la estabilidad de las repúblicas: el hombre no cambia la ley de la historia, pero utiliza esa ley en función de un fin que él mismo se ha propuesto.

En este marco se inscribe la meditación de Maquiavelo sobre la virtud y la fortuna. La "rueda de la fortuna" es en principio, en el ámbito sociopolítico, esa rueda de las formas de gobiemo a la que nos hemos referido. Sin embargo, los 
hombres y las repúblicas pueden conseguir obtener buena o mala fortuna para sí (es la "suerte" o fortuna en sentido subjetivo), en la medida en que ajustan su proceder a los tiempos y circunstancias ${ }^{28}$. Claro está que para este ajuste el margen de libertad no es muy amplio, y por eso Maquiavelo subraya que lo ideal es que las circunstancias extermas coincidan con la propia naturaleza y estilo29, pues ahí la fortuna depende enteramente de las leyes de la naturaleza humana y no de un cálculo o de una decisión. Aún así, Maquiavelo no deja de reconocer a esta naturaleza humana y al estilo del político o de las repúblicas mismas un cierto carácter moral: es lo que él denomina la virtú. En los contratiempos el hombre virtuoso permanece fiel a sí mismo, mientras que en el éxito es modesto y realista, no atribuyéndose a sí mismo lo que en realidad es acción de la fortuna. Todo lo contrario de lo que sucede en el caso de las personas mezquinas ${ }^{30}$. La virtud es, en este sentido, tanto la capacidad de captar la oportunidad histórica que brinda la fortuna para determinar favorablemente el curso de los acontecimientos, como lo que los clésicos denominaban areté, es decir, una fuerza o valor que emerge de la propia naturaleza humana y que, por tanto, podría ser reducido a un factor más de la fortuna. En el fondo de la concepción "maquiavélica" del hombre late una terrible dualidad entre libertad y determinismo que no es otra cosa que la dualidad misma de la concepción moderna de lo real.

\section{Dualismo cartesiano.}

En último término, podríamos quizás concluir que el modelo de realidad que Maquiavelo maneja es, más que una mera recaída en el esquema helénico del etemo retomo, un producto típicamente modemo. El concepto de realidad de la modemidad europea se funda justamente sobre el descubrimiento galileano de que "el libro de la naturaleza está escrito con caracteres matemáticos". Esta matematización, que deja decididamente de lado la idea de Giordano Bruno de un universo orgánico, es para la modemidad equivalente de una mecanización. El mundo puede ser interpretado en términos de estrictas necesidades físicas. El ámbito biológico no hace excepción: pertenece a la materia extensa y ha de ser explicado more geometrico. Sin embargo, hay para la modemidad una realidad que escapa a esta grandiosa metáfora de la máquina: es justamente el ego pensante de Descartes, ámbito del espíritu, de la espontaneidad y de la libertad. No puede haber realidades más heterogéneas que la máquina y el espíritu. La historia de la filosofia modema hasta Hegel da buena muestra de la paradoja que esta dualidad radical representa y de la dificultad de hallar una síntesis que vaya más allá de la yuxtaposición kantiana o de la supresión de uno de los polos (la libertad), como sucederá en la filosofía ilustrada de la historia.

Maquiavelo vive en los albores de la modemidad esta paradoja, sin ser un metafísico y sin planteársela explícitamente. El dominio libre de la realidad y su transformación presuponen un conocimiento científico del mundo. $Y$ este conocimiento supone encontrar leyes estrictas. Ahora bien, una vez encontradas estas 
leyes en el mundo sociopolítico, parece que el margen de acción libre que Maquiavelo no puede menos de presuponer en sus lectores se estrecha más y más. ¿Cómo tratar al hombre político al mismo tiempo como objeto y como sujeto? Tal vez no se puede pedir a Maquiavelo la solución de esta paradoja de la metafísica modema. Pero sí la constatación ingenua de la imposibilidad de encontrar, dentro de tales supuestos, una verdadera síntesis: "los hombres - dirá Maquiaveloobran por necesidad o por libre elección, y vemos que hay mayor virtud allí donde la libertad de elección es menor" ${ }^{\prime 3}$. Sin embargo hay en la obra de Maquiavelo observaciones que apuntan más allá de este dualismo modemo entre fortuna y libertad. Con fino sentido sociológico, Maquiavelo constata la fuerza que las costumbres tienen en la vida de las repúblicas ${ }^{32}$. Por ello, el legislador y el político ha de intentar que sus leyes se asienten sobre las costumbres del mismo modo que las buenas costumbres se han de conservar mediante las leyes adecuadas: se trata de una acción recíproca entre lo meramente jurídico y la moral socialmente acepta$\mathrm{da}^{33}$. Aquí estamos en un ámbito que no es clasificable ni como mera necesidad ni como pura libertad. Es justamente el ámbito de la acción social, no reductible ni a la lógica de la fortuna ni a la de la decisión subjetiva arbitraria ${ }^{34}$.

Ciertamente, Maquiavelo no dispone de las categorías adecuadas para pensar esta realidad, de modo que con frecuencia pone en el mismo nivel la fuerza de la naturaleza y la de los imperativos sociales ${ }^{35}$. Aquí hubiera sido menester desarrollar un concepto que está más allá de la necesidad y de la simple libertad: es justamente la idea de posibilidad, que alguna vez apunta en el texto ${ }^{36}$, pero que no es considerada temáticamente. Se podría sin duda decir que Maquiavelo, aunque no se sirva de esta categoría, se mueve en un tipo de análisis que de hecho la supone: el ámbito de la acción política es justamente el campo de lo posible, y Maquiavelo lo sabe tanto cuando trata de dar consejos al político como cuando describe leyes necesarias. En el fondo no quiere otra cosa que tratar de determinar esas posibilidades que no dependen ni de la pura espontaneidad del político ni de las leyes naturales. Esto es sin duda así. Lo único que aquí se pretende mostrar es que Maquiavelo no dispone de una idea de realidad adecuada para tematizar esto. Ha quedado preso del concepto de una naturaleza humana individual de la que se pueden determinar sus leyes universales de comportamiento.

Con todo, el concepto de realidad de Maquiavelo tiene una ventaja sobre el helénico: aquí la república no es un organismo vivo dotado de una esencia inmutable, sino un constructo de los hombres particulares. De este modo, la idea típicamente modema de que el estado nacional es el ámbito de toda valoración éticopolítica en términos de derecho o de justicia, no es en Maquiavelo una necesidad natural. De hecho, aunque el secretario florentino añore una unificación italiana, su marco de referencia es la pequeña ciudad-república. Pero - a título de hipótesis- si la república es un constructo, su concepto de la realidad está al menos 
potencialmente abierto para pensar una realidad comtemporánea que supera los marcos estrechos del estado nacional: se trata de la sociedad mundial surgida en los últimos siglos de la historia humana. Lamentablemente, esta potencialidad de la idea de realidad de Maquiavelo es en fondo una mera consecuencia de su atomismo individualista.

\section{Notas}

1. Cfr. A. RENAUDET, Maquiavelo, Madrid, 1965, pp. 137-164.

2. Cfr. N. MAQUIAVELO, Discursos sobre la primera década de Tito Livio, Madrid, 1987, p. 33.

3. Cfr. su «Introducción» a la citada edición española de los Discursos de Maquiavelo.

4. Cfr. ibid., p. 11.

5. Cfr. ibid., p. 13.

6. Ibid., p. 14.

7. Cfr. ibid., pp. 25-27.

8. Cfr. ibid, 177-180.

9. Cfr. ibid., pp. 27-27.

10. Cfr. ibid. pp. 35.

11. Ibid.

12. Ibid.

13. Cfr. ibid., pp. 384ss, 401, 330ss.

14. Ibid., p. 67.

15. Cfr. ibid. p. 37.

16. Cfr. ibid., p. 39.

17. Cfr. ibid., p. 290.

18. Cfr. ibid., pp. 27ss.

19. Cfr. ibid., p. 35.

20. Cfr. ibid., p. 385.

21. Cfr. ibid., p. 32

22. Cfr. A. RENAUDET, op. cit., pp. 153s.

23. Cfr. N. MAQUIA VELO, Discursos sobre la primera década de Tito Livio, op. cit., pp. 289ss.

24. Cfr. ibid., p. 290.

25. Cfr. ibid., p. 122.

26. Cfr. ibid., pp. $27 s s .8$

27. Cfr. ibid., pp. 35ss.

28. Cfr. ibid., pp. 330ss, $401 \mathrm{~s}$.

29. Cfr. ibid., pp. 330s.

30. Cfr. ibid., pp. 384ss.

31. Ibid., p. 29.

32. Cfr. ibid., pp. 120 ss

33. Cfr. ibid., p. 84.

34. Cfr. ibid., p. 401.

35. Cfr. ibid., p. 30.

36. Cfr. ibid., p. 48. 